\title{
Impact of Eradication Programs on the Temporal and Spatial Dynamics of Plum pox virus on Prunus spp. in Pennsylvania and Ontario, Canada
}

\author{
A. V. Gougherty and F. W. Nutter, Jr., Department of Plant Pathology and Microbiology, Iowa State University, Ames 50011
}

\begin{abstract}
Gougherty, A. V., and Nutter, F. W., Jr. 2015. Impact of eradication programs on the temporal and spatial dynamics of Plum pox virus on Prunus spp. in Pennsylvania and Ontario, Canada. Plant Dis. 99:593-603.

The goals of this research were to quantify the impacts of the Pennsylvania and Ontario Plum pox virus (PPV) eradication programs on the spatial and temporal dynamics of PPV epidemics on Prunus spp. The incidence of PPV-positive trees detected over time decreased in both Pennsylvania ( $-\ln 0.85$ units per year) and Ontario ( $-\ln 0.51$ units per year); however, PPV incidence per year decreased only $60 \%$ as fast in Ontario as in Pennsylvania. Marked point pattern analysis revealed that PPV-positive Prunus blocks in Pennsylvania were clustered for distances of 0.7 to $4.3 \mathrm{~km}$, whereas PPV-positive blocks in Ontario were clustered for distances of 1.0 to $25.0 \mathrm{~km}$. Multiyear spatiotemporal analyses revealed that the locations of PPV-positive blocks detected were spatially dependent upon the locations of PPV-positive blocks detected during the previous year. In Pennsylvania, between 2002 and 2006,

distances to $95 \%$ of newly detected PPV-positive blocks occurred within 10 and $20 \mathrm{~km}$ from the previous year's PPV-positive blocks. In Ontario, 95\% of new PPV-positive blocks occurred within 500 to 900 $\mathrm{m}$ from PPV-positive blocks detected the previous year. Until 2011 , the PPV eradication policy for Prunus blocks in Ontario was triggered by a threshold incidence or PPV-positive tests for three consecutive years. Although the Ontario program was highly successful in reducing PPV incidence from 2001 to 2008 , PPV was not eradicated. This study provides important quantitative information concerning the impact of PPV eradication programs on the spatial and temporal dynamics of PPV epidemics in Pennsylvania and Ontario. The analyses employed in this study may help to improve the effectiveness of present and future PPV eradication programs.
\end{abstract}

Plum pox virus (PPV), also known as sharka disease, is one of the most damaging pathogens of Prunus spp. worldwide (5), causing severe reductions in both fruit yield and quality (24). In some countries where PPV is well established, documented crop losses have approached $100 \%$ (24). Since PPV was first detected in Bulgaria in 1915 (1), PPV has been reported to occur throughout much of western Europe $(6,21,23,30,44)$, the Mediterranean $(2,4,12,20,28,45,53)$, the Middle East (56,58), Asia (34), and South America (31,40). PPV was first detected in North America in Pennsylvania in 1999 (25) and in Ontario and Nova Scotia, Canada, in 2000 (50). In 2006, the presence of PPV was also confirmed in New York and Michigan (43). The detection in Michigan involved a single tree, which was destroyed; since then, there have been no new positives detected in Michigan. The PPV epidemic in New York, however, is still ongoing (33).

Because of the severe negative impacts that PPV has on stone fruit (5), PPV is classified as a quarantine pathogen by numerous plant protection organizations, including the North American Plant Protection Organization (NAPPO) $(29,32,51)$. Following the detection of PPV in the United States and Canada, both countries established national PPV survey and eradication programs $(49,51)$. The two North American eradication programs differ in a number of ways, including sampling protocols employed, number of leaves sampled per tree, brand of commercial enzyme-linked immunosorbent assay (ELISA) kits (and protocols) used to test bulk leaf samples, and how each eradication policy is implemented once a PPV-positive Prunus tree or block (a group of trees of the same species and age, grown in the same location) is detected $(49,51)$. Although PPV was officially declared eradicated in Pennsylvania in 2009 (according to NAPPO guidelines) (32), PPV has yet to be eradicated in Ontario and New York $(7,33)$.

When a nonindigenous plant pathogen (such as PPV) is first detected and confirmed in a new geographic area (county, province,

Corresponding Author: F.W. Nutter, Jr., E-mail: fwn@iastate.edu

Accepted for publication 2 October 2014.

http://dx.doi.org/10.1094/PDIS-03-14-0224-RE

(C) 2015 The American Phytopathological Society state, or country), a critical question immediately arises: can the new threat be eradicated? The answer is dependent on the geospatial extent of the infestation, pathogen dispersal mechanisms, the biology of both the vector (11) and the pathogen (41), and other host characteristics (e.g., extent and density of plantings as well as susceptibility) (9).

Exclusion and eradication are two key management principles that most often come into play when a nonindigenous pathogen poses a new threat to an agricultural industry $(37,38)$. In order to be effective, exclusion requires science-based information about where the pathogen occurs. Quarantined areas may be subjected to intensive sampling and testing protocols, as with PPV eradication programs in both Pennsylvania and Ontario, Canada.

Both Ontario and Pennsylvania have conducted PPV survey and eradication programs to identify and remove infectious trees. For roguing to be effective in eradication schemes, sampling and testing protocols are developed to correctly identify which Prunus trees and blocks are infected $(35,39,48,49)$. However, the impact of U.S. and Canadian PPV eradication programs on temporal and spatial dynamics of PPV epidemics has not been assessed. The objectives of this study were to (i) quantify the temporal dynamics of PPV epidemics in Pennsylvania and Ontario since the implementation of PPV exclusion and eradication programs, (ii) determine the spatial pattern of PPV-positive blocks for each PPV survey year (that GPS data were available), and (iii) determine within-block spatial patterns of PPVpositive trees in Ontario, Canada.

\section{Materials and Methods}

PPV survey data were obtained from the Pennsylvania Department of Agriculture (PDA) and the Canadian Food Inspection Agency (CFIA) (18). Generally, survey data included the GPS locations of all PPV-positive and all PPV-negative Prunus blocks surveyed. Pennsylvania survey data comprised the locations of all Prunus blocks surveyed from 1999 through 2006 (the final year that PPVpositive blocks were detected). Survey data from Ontario consisted of Prunus blocks surveyed from 2006 through 2009, because GPS spatial data for Prunus blocks were not collected before 2006.

In Pennsylvania, survey crews visited all Prunus blocks in the state during each growing season. In nonquarantined areas where the status of PPV was still unknown or the virus had not yet been detected, 
a systematic hierarchical sampling design was employed to select trees for leaf sampling and testing (51). Within quarantined areas where PPV had previously been detected, all Prunus trees within all Prunus blocks were sampled each year (51). Survey crews in Pennsylvania were instructed to collect eight Prunus leaves from each tree that was sampled and each eight-leaf sample was then bulk tested for the presence of PPV using a commercially available ELISA kit. From 1999 through 2005, Pennsylvania used an ELISA kit produced in Spain (Durviz Inc., Valencia, Spain) (54). After the 2005 growing season, however, the United States Department of Agriculture Animal and Plant Health Inspection Service adopted a doubleantibody sandwich ELISA kit manufactured by Agdia Inc. (Elkhart, IN) (51). The Pennsylvania protocol assumes that at least one of the eight Prunus leaves in a bulk sample must be PPV-positive in order for a bulk sample to test positive for PPV. When a PPV-positive tree was detected in Pennsylvania, the PPV-positive block and all other Prunus spp. blocks within a 500-m buffer zone (from the edges of each PPV-positive block) were removed (eradicated) (51).

As in Pennsylvania, Prunus blocks in Ontario located outside established quarantine areas were sampled less intensively than Prunus blocks located within established PPV quarantine zones. Quarantine zones extend for a distance of $1,500 \mathrm{~m}$ from the locations of all previously detected PPV-positive trees or blocks (49). In nonquarantine zones, leaf samples were collected from approximately $25 \%$ of the trees within each Prunus block, using a hierarchical sampling design (49). All trees in Prunus blocks that previously tested positive for PPV were tested for PPV by ELISA. The Ontario sampling protocol required that 20 leaves be collected from each sampled tree (5 per scaffold). Each 20-leaf bulk sample was then tested by ELISA. In early years of the Ontario PPV survey, 12 leaves per tree were sampled and bulk tested (49). Since its inception, the Ontario PPV Eradication Program used an ELISA kit manufactured by Durviz, Inc. to test for the presence of PPV.

Temporal progress of PPV epidemics. The number of PPVpositive Prunus trees detected in Pennsylvania and Ontario was plotted over time (2001 to 2010). Five population growth models (linear, monomolecular, exponential, logistic, and Gompertz) were evaluated to determine which model best fit the relationship between the transformed frequency of PPV-positive trees detected (y) versus year of detection $(x)(35,57)$. The incidence of PPVpositive trees (the number of PPV-positive trees/total number of trees sampled and tested $\times 100$ ) was also plotted over time and the five population growth models were similarly evaluated. Models were evaluated using least squares regression based on the following criteria: a significant $F$ statistic $(P \leq 0.05)$ for the overall model, the coefficient of determination $\left(R^{2}\right)$ using the backtransformation method, the standard error for the estimate for $y$ (SEEy), and the visual inspection of residual plots $(52,35,46)$.

Seasonal patterns of PPV detection. To determine whether time of sampling (week) affected the frequency of PPV-positive trees detected during a growing season, the frequency of PPV-positive trees was plotted versus week of sampling.

Spatial analyses of PPV-positive blocks. Ripley's K function was used to characterize the spatial patterns of PPV-positive Prunus blocks $(13,42)$. In Pennsylvania, an orchard block is defined as the planting of a given Prunus sp. whereas, in Ontario, an orchard block is defined as the planting of a single cultivar of a given Prunus sp. The K function utilizes a marked point process to characterize the patterns of completely mapped points (37). Ripley's K is calculated by comparing the density of marked points (PPV-positive blocks) within a given radius around each single marked point to the density of all marked points in the study area. The $\mathrm{K}$ function is given as:

$$
\begin{aligned}
\mathrm{K}(d)= & \lambda^{-1} \mathrm{E}[\text { number of extra marked points within } \\
& \text { distance } d \text { of a randomly chosen marked point }]
\end{aligned}
$$

where $\lambda$ is the density of all marked points. This process is repeated for all marked points in the study area and for all distance intervals defined by the user $(13,37)$.
Spatial dependence is determined by calculating the K function for a simulation of randomized points, which is then compared with the observed $\mathrm{K}$ function obtained from the known GPS locations of marked points (e.g., PPV-positive blocks). If the observed $\mathrm{K}(d)$ for a given distance is greater than the simulated $\mathrm{K}(d)$ for that distance, then the marked points are considered spatially dependent (clustered) at that distance $(13,37)$. Similarly, if the observed $\mathrm{K}(d)$ for a given distance is less than the simulated $\mathrm{K}(d)$, then marked points are considered regularly distributed at that distance. Finally, when the observed $\mathrm{K}(d)$ is within the simulated upper and lower confidence envelopes, marked points (PPV-positive Prunus blocks) are considered randomly distributed for that distance.

Because the spatial pattern of all Prunus blocks, regardless of PPV status, is not random in either Pennsylvania or Ontario, a random labeling null hypothesis was used to calculate the simulated confidence envelopes $(13,55)$. This null hypothesis allowed for determination of whether the spatial pattern of PPV-positive Prunus blocks was significantly different from the underlying pattern of all Prunus blocks $(13,55)$. The random labeling null hypothesis uses a Monte Carlo simulation to randomly label the status of marked points (i.e., the status of Prunus blocks as being either PPV positive or PPV negative). Ripley's K is calculated for the randomly labeled points to generate a confidence envelope, from which spatial dependence (PPV spatial pattern) is then inferred. Visual interpretation of the plotted $\mathrm{K}$ function is more intuitive using a transformed version, known as the $\mathrm{L}$ function (13). The $\mathrm{L}$ function stabilizes the variance and removes the scale dependence associated with the K function (13,55). Plots, therefore, were generated using the L function, which is given as:

$$
\mathrm{L}(d)=\sqrt{\frac{\mathrm{K}(d)}{\pi}}-d
$$

The univariate $\mathrm{L}$ function was calculated for individual years of PPV-positive blocks (9). The $\mathrm{L}$ function requires at least 30 marked points (i.e., PPV-positive blocks); hence, for Pennsylvania, the L function was calculated only for the positive blocks detected in 2000 , because all subsequent survey years had fewer than 30 PPVpositive Prunus blocks detected, which prohibited the use of this analysis for Pennsylvania after 2000. For Ontario, the L function was calculated for PPV-positive blocks for the years that GPS data were available (2006 through 2009).

A bivariate form of the $\mathrm{K}$ function was used to assess the presence of spatial dependence over consecutive survey years (13). This analysis allows for the determination of whether the locations of PPVpositive blocks in one year are spatially dependent upon the locations of PPV-positive blocks detected the previous year. The bivariate K function is given as:

$$
\begin{aligned}
\mathrm{K}_{i j}(d)= & \lambda_{j}^{-1} \mathrm{E}[\text { number of type } j \text { marked points within } \\
& \text { distance } d \text { of a randomly chosen type } i \text { marked point }]
\end{aligned}
$$

where $\lambda_{j}$ is the density of $j$ marked points. For our purposes, " $i$ marked points" are PPV-positive blocks from year 1 and " $j$ marked points" are PPV-positive blocks from year 2. As with the univariate calculation, a random labeling null hypothesis was most appropriate, and the bivariate $\mathrm{K}$ function was transformed to the $\mathrm{L}$ function using the above equation. The bivariate $\mathrm{L}$ function was calculated for three pairs of consecutive survey years in Ontario (i.e., 2006 and 2007, 2007 and 2008, and 2008 and 2009). The univariate and bivariate L functions were calculated in each instance using the software program PROGRAMITA (55).

We developed a method to determine the distance to 50 and $95 \%$ of new PPV-positive blocks ( $\mathrm{D}_{50}$ and $\mathrm{D}_{95}$, respectively) relative to the GPS locations of the previous year's PPV-positive blocks $(16,18)$. The $D_{50}$ and $D_{95}$ were calculated for each available year of data by determining the nearest-neighbor distance from each PPV-positive block in a specific year to all newly detected PPVpositive blocks the ensuing year. Nearest-neighbor distances were calculated using ArcMap software (Environmental Systems Research Institute, Redlands, CA). The nearest-neighbor distances 
(for each pair of consecutive years) were then divided into 50 and 95\% quantiles and plotted over time (year).

Spatial analysis within PPV-positive blocks. To determine the spatial pattern (regular, clustered, or random) of PPV-positive trees within PPV-infected blocks in Canada, all trees within 12 individual Prunus blocks were mapped with regard to their PPV status (positive or negative). Twelve Prunus blocks that had previously tested positive for PPV were arbitrarily selected for this analysis by CFIA personnel. Each tree in each block was individually sampled and tested for PPV using an ELISA kit (Durviz Inc.) by the CFIA (47). Ordinary runs analysis was used to determine how the PPV-positive trees were distributed within the block $(3,19,27,46)$. A run is defined as a sequence of like events (27). Here, a run was a sequence of healthy or PPV-infected Prunus trees, either within or across tree rows. To determine the presence of spatial dependence (clustering) of PPV-infected trees within a Prunus block, a $z$-statistic was calculated to compare the observed number of runs to the expected number of runs that would occur if PPV-positive trees were randomly distributed within a block, for a given level of PPV incidence (27). The $z$ statistic is calculated as:

$$
z=\frac{\mathrm{O}-\mathrm{E}}{\mathrm{s}(\mathrm{O})}
$$

where $\mathrm{O}$ is the observed number of runs, $\mathrm{E}$ is the expected number of runs, and $\mathrm{s}(\mathrm{O})$ is the standard deviation of the observed number of runs. A $z$-statistic $<-1.64$ indicates that PPV-positive trees are spatially clustered within a Prunus block (rejection of the null hypothesis for randomness) (19,27). Conversely, a $z$-statistic $>-1.64$ indicates that PPV-positive trees are randomly distributed within a Prunus block. A $z$-statistic was calculated for each of the 12 blocks both within and across tree rows.

Spatiotemporal analysis. A distance-based analysis was used to determine whether PPV-positive trees detected in subsequent years were spatially dependent upon PPV-positive trees detected in preceding years (22). Distances from previous years' PPV-positive trees to all newly detected PPV-positive trees within the same block in subsequent years were calculated and averaged. If PPVpositive trees were within the distance of the nearest $5 \%$ of all Prunus trees from previously positive trees, this distance was determined to be significant $(P \leq 0.05)$.

\section{Results}

Temporal progress of PPV epidemics in Pennsylvania and Ontario. In general, the number of PPV-positive trees detected in both Pennsylvania and Ontario decreased after PPV eradication programs were first implemented. In Pennsylvania, the number of PPV-positive Prunus trees detected between 2000 and 2006 decreased exponentially from a maximum of 399 in 2000 to 6 in 2006 and then 0 in 2007, 2008, and 2009 (Fig. 1A). Using the best-fit model (exponential), the independent variable (year) explained $62.8 \%$ of the variation in the reduction in $\ln$ (number of PPV-positive trees) detected over time $\left(R^{2}=62.8 \%\right)$ (Fig. 1C). In Ontario, however, the number of PPV-positive Prunus trees first increased from 940 in 2000 to 1,474 in 2001, decreased linearly to 133 in 2008, then increased to 142 in 2009 and 211 in 2010. Using the linear model, the number of PPV-positive trees detected between 2001 and 2008 in Ontario decreased by approximately 157 trees per year (Fig. 1B and D), with year explaining 84.7\% of the variation in the decline in PPV-positive trees detected per year. From 2008 through 2010, the number of newly detected
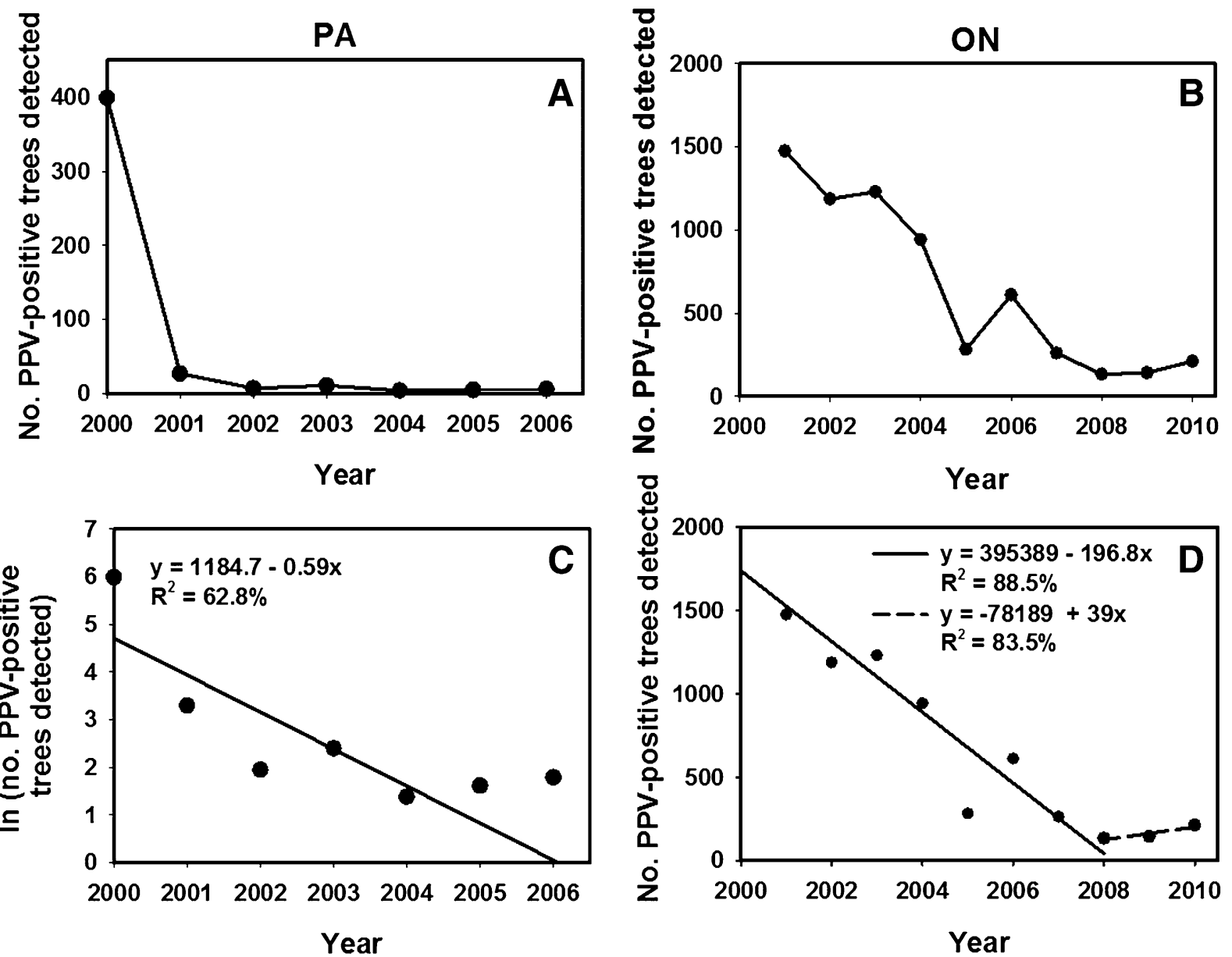

Fig. 1. Number of PPV-positive Prunus trees detected over time in A, Pennsylvania (PA) and B, Ontario (ON); and C, the In number of PPV-positive trees regressed over time in Pennsylvania and $\mathbf{D}$, linear regression of PPV-positive trees over time in Ontario, Canada. 
PPV-positive trees increased by approximately 39 trees per year $\left(R^{2}=83.5 \%\right)$.

PPV incidence (number of PPV-positive trees/total number of Prunus trees sampled and tested $\times 100$ ) in both Pennsylvania and Ontario decreased exponentially over time (Fig. 2). Incidence of PPV was highest in Pennsylvania in 2000 (0.76\%) and was $1.07 \%$ in Ontario in 2001, the year after PPV eradication surveys in Ontario were initiated (in 2000). PPV incidence decreased substantially in subsequent years, falling below $0.05 \%$ in 2001 in Pennsylvania (Fig. 2A) and to $<0.05 \%$ in Ontario by 2007 (Fig. 2B). In 2008 and 2009, PPV incidence in Ontario remained below $0.05 \%$.

PPV incidence over time was best fit by the negative exponential model $\left(R^{2}=72.1 \%\right.$ for the Pennsylvania data and $88.4 \%$ for the Ontario data). Other model criteria ( $F$ statistics for the overall models, SEE $y$ values, and patterns of residuals versus year) also indicated that the negative exponential model provided the best fit. Therefore, PPV incidence was transformed using the negative exponential model to obtain a linear relationship between time (year) and $\ln$ (incidence). This model was then used to quantify the impacts of the eradication programs on PPV incidence over time. Because the same model could be used to quantify the reduction in PPV incidence over time, the resulting regression coefficients $(r)$ were used to compare efficacy of the eradication programs. The regression coefficients relating reduction in $\ln$ (incidence) over time were -0.506 ( $F=12.93$, $P=0.0156)$ for Pennsylvania and -0.846 for Ontario $(F=86.29$, $P<0.0001$ ) (Fig. 2C and D).

Decline in PPV-positive blocks over time. The number of PPVpositive Prunus blocks decreased over time (Fig. 3). In Pennsylvania, 41 blocks were detected in 2000, and the number of new PPV-positive blocks decreased at a rate of -0.44 blocks per year in subsequent years $\left(R^{2}=80.5 \%\right)$. The number of PPV-positive blocks in Ontario also tended to decrease over time, despite increases in 2004 and 2006 (Fig. 3B). Based upon ordinary least squares regression, approximately 16 fewer PPV-positive blocks were detected each year $\left(R^{2}=45.2 \%\right)($ Fig. 3D).

Seasonal patterns of PPV detection at the tree scale. Frequency of PPV-positive trees detected over time had a strong seasonal pattern in both locations (Fig. 4). In Pennsylvania, the frequency of PPV-positive trees detected between 2000 and 2006 peaked in week-of-year 20 and then decreased sharply in following weeks. In Pennsylvania, 90\% of PPV-positive trees were detected by week 27. For the years in which GIS data were available in Ontario (2006 through 2009), frequency of PPV-positive trees peaked in week 24 and then decreased steadily over the remaining sampling period. Over this time period (2006 to 2009), 90\% of PPV-positive trees detected in Ontario were detected by week 34.

Spatial distribution of PPV-positive Prunus blocks. PPVpositive blocks in Pennsylvania in 2000 were significantly more clustered than the spatial pattern of all Prunus blocks for distances of 0.7 to $4.3 \mathrm{~km}$ but not at shorter or longer distances (Fig. 5). In Ontario, PPV-positive blocks were significantly more clustered than all Prunus blocks for distances of 1.0 to $25.0 \mathrm{~km}$ (Fig. 6).

Applying the bivariate form of Ripley's K function to consecutive years of PPV survey data in Ontario, PPV-positive Prunus blocks were significantly clustered in 2007 within 0.1 to $3.0 \mathrm{~km}$ of the previous year's PPV-positive blocks (Fig. 7A). In 2008, PPV-positive blocks were significantly clustered within distances of 0.1 to $17 \mathrm{~km}$ from blocks that had tested positive for PPV in 2007 (Fig. 7B).
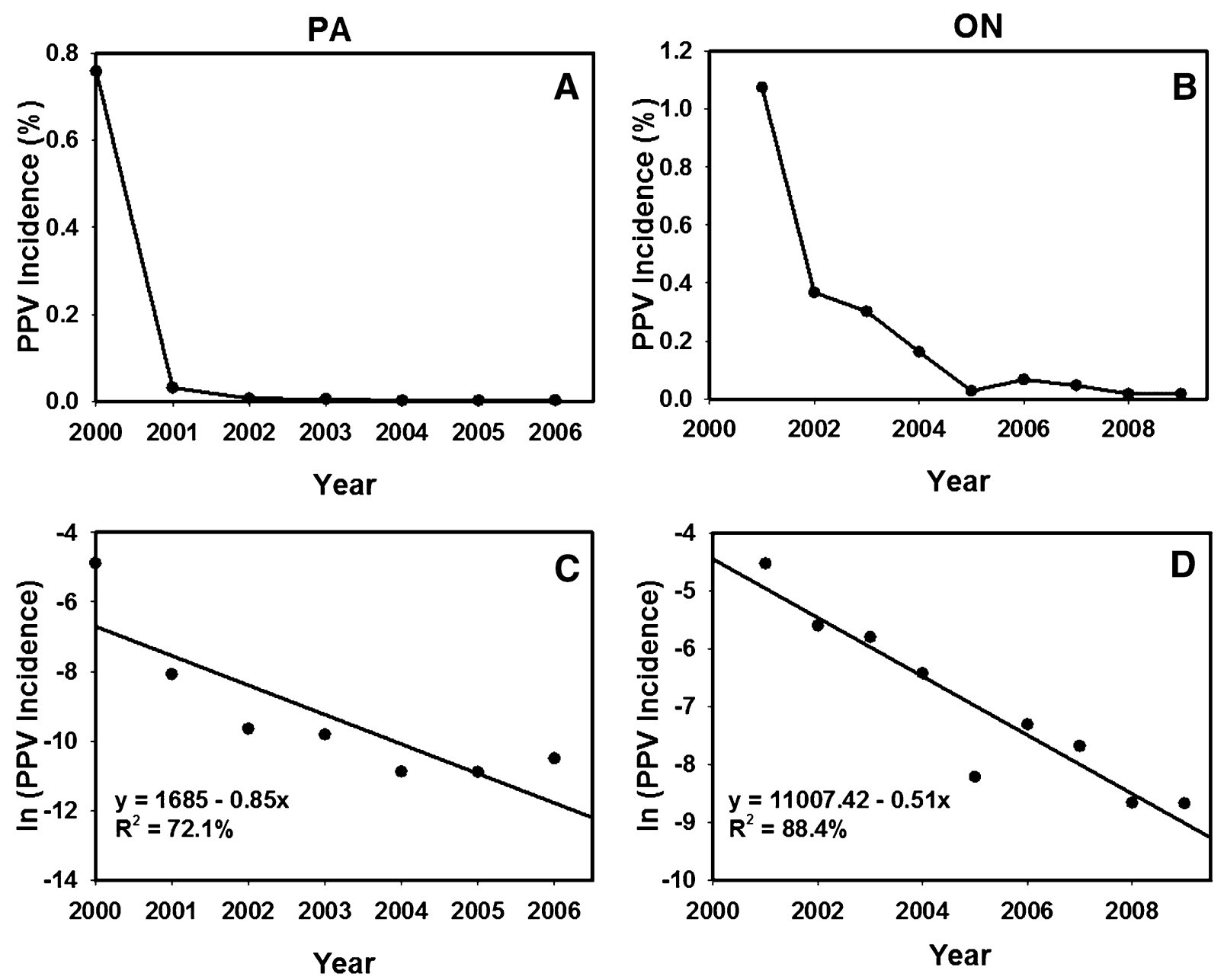

Fig. 2. Incidence of PPV-positive Prunus trees over time in A, Pennsylvania (PA) and B, Ontario (ON); and C, In PPV incidence over time in Pennsylvania and D, PPV incidence, regressed over time in Ontario, Canada. 
In 2009, PPV-positive blocks were significantly clustered for distances between 0.1 to $17.4 \mathrm{~km}$ from Prunus blocks that were PPVpositive in 2008 (Fig. 7C). This analysis was not possible for the Pennsylvania data because the bivariate $\mathrm{K}$ function requires a minimum of at least $30 \mathrm{PPV}$-positive blocks for both years.

Distance from PPV-positive blocks to 50\% of new PPV-positive blocks $\left(D_{50}\right)$ in Pennsylvania increased from $1.3 \mathrm{~km}$ in 2000 to a maximum of $17.1 \mathrm{~km}$ in 2005, indicating that PPV-positive blocks in Pennsylvania were expanding (spatially) relative to previous years during this period (Fig. 8). In 2006, however, $\mathrm{D}_{50}$ values decreased to $6.3 \mathrm{~km}$. In 2001, $\mathrm{D}_{95}$ values initially increased to a maximum of $34.6 \mathrm{~km}$ in Pennsylvania, then decreased to 11.2 $\mathrm{km}$ in 2004. The distance to 95\% of new PPV-positives in Pennsylvania then increased in 2006 to a distance of $19.7 \mathrm{~km}$. In Ontario, $D_{50}$ values increased each year from 2007 to 2009 (Fig. 9), and $D_{95}$ values first decreased slightly between 2007 and 2008, and then increased in 2009.

Spatial pattern of PPV-positive trees within Prunus blocks in Ontario. The spatial pattern of PPV-positive trees within rows of Prunus blocks was random for 9 of the 12 Prunus blocks analyzed (Table 1). In the remaining three blocks, the spatial patterns of PPV-positive Prunus trees within rows were significantly clustered $(P \leq 0.05)$. Across rows, the spatial patterns of PPV-positive trees were random in 10 of 12 Prunus blocks (Table 1) and significantly clustered across rows for the remaining blocks $(z<-1.64)$. This analysis was not possible for Prunus blocks in Pennsylvania because entire PPV-positive blocks were removed during the same season that PPV was detected.

PPV-positive trees were not significantly clustered near the previous year's PPV-positive trees in 10 of the 12 Prunus blocks analyzed in Ontario. In two blocks, however, trees that tested positive in 2010 were significantly $(P \leq 0.05)$ clustered around the previous year's PPV-positive trees.

Simulating a removal policy in Ontario based on distance rather than PPV incidence thresholds within blocks revealed that the percentage of future PPV-positive blocks that would have been removed increased as block removal distance increased (Fig. 10). Percentage

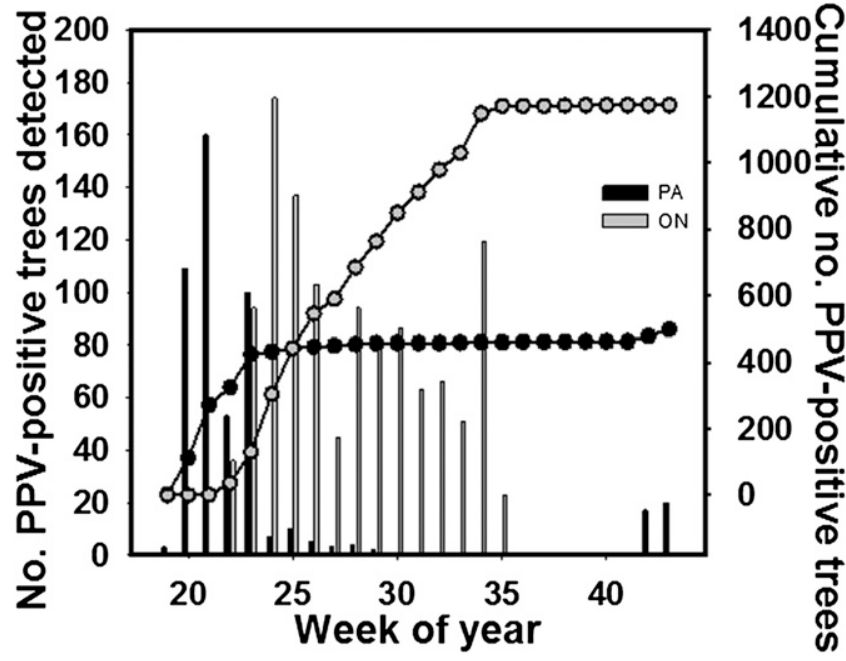

Fig. 4. Number and cumulative number of PPV-positive trees detected in Pennsylvania (1999 to 2006, black) and Ontario (2006 to 2009, gray) with respect to week of sampling.
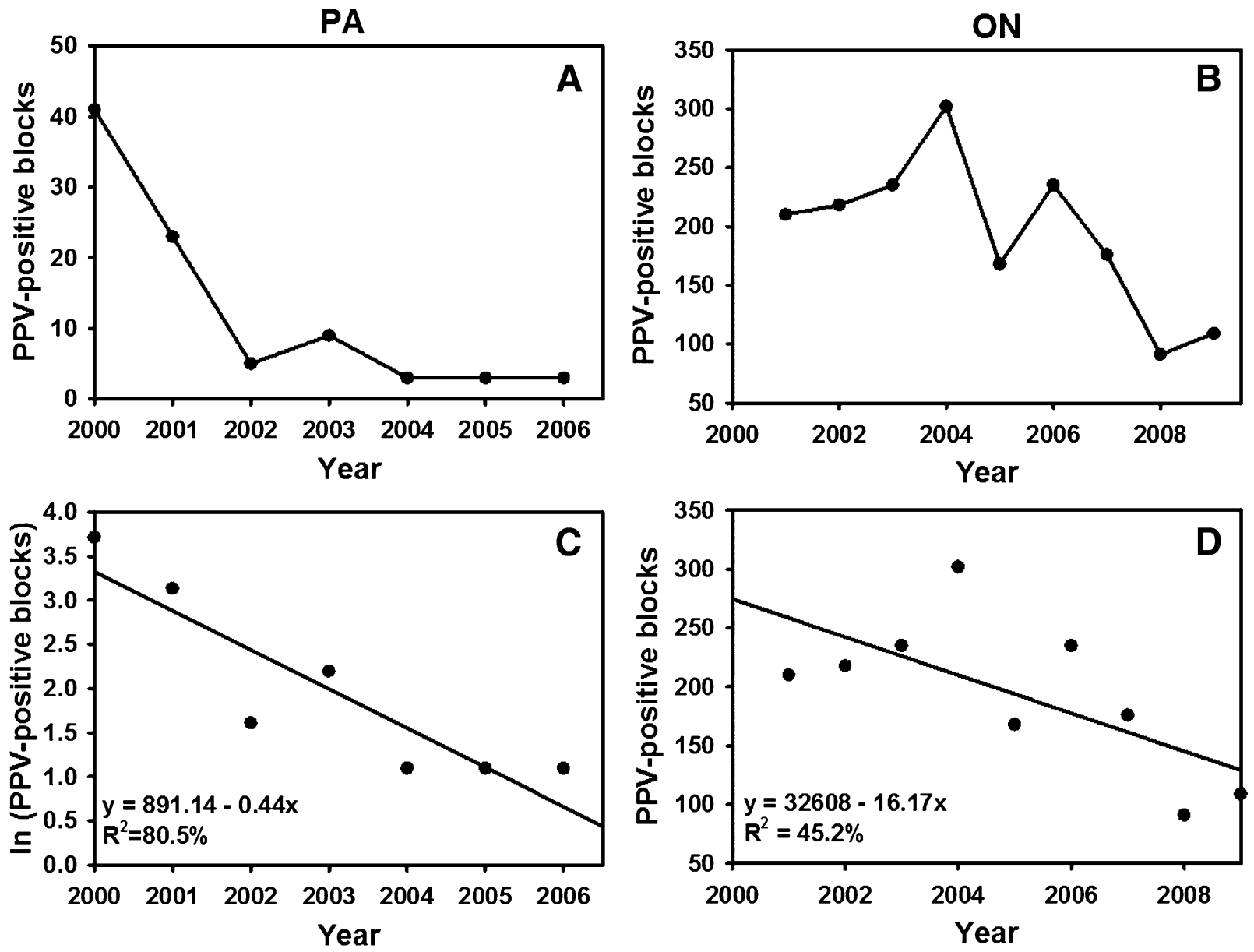

Fig. 3. Number of PPV-positive Prunus blocks detected each year in A, in Pennsylvania (PA) and B, in Ontario (ON); and C, regression of In PPV-positive Prunus blocks over time in Pennsylvania and D, linear regression of PPV-positive blocks over time in Ontario, Canada. 
of healthy Prunus blocks that would have also been removed similarly increased as removal distance increased. If a 500-m removal distance was implemented in Ontario, as it was in Pennsylvania,

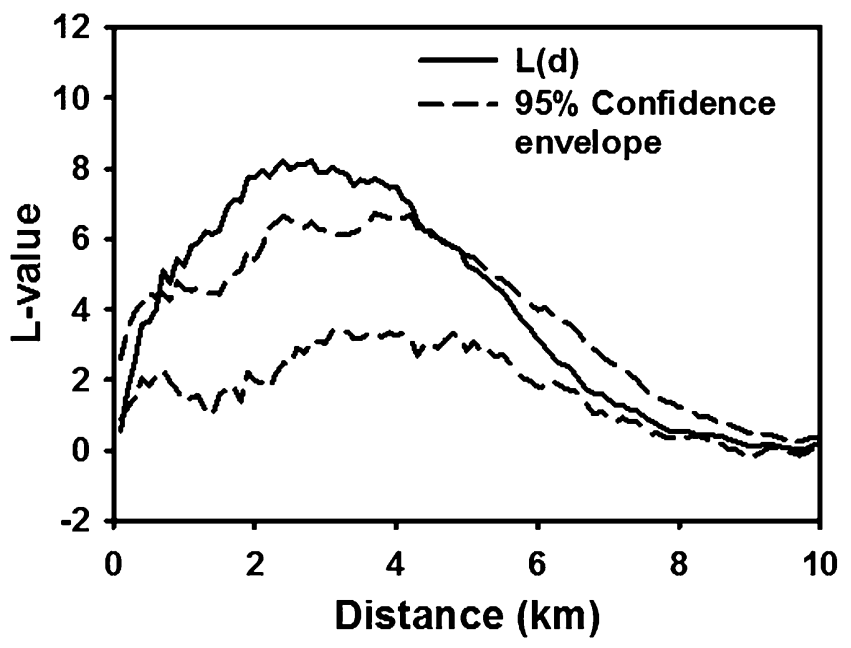

Fig. 5. Ripley's $L$ function (solid line) using a random labeling null hypothesis to analyze the spatial dependence of PPV-positive Prunus blocks detected in Pennsylvania in 2000. Dashed lines are a 95\% confidence envelope based on a simulated randomized labeling of all Prunus blocks. The observed $L$ function (solid line) within the confidence envelope (dashed lines) indicates a random pattern, above the confidence envelope a clustered pattern, and below the confidence envelope a dispersed pattern.
91.2\% of future PPV-positive blocks would have been removed (Fig. 11), along with approximately $41.3 \%$ of the healthy blocks. For every $1 \%$ increase in the percentage of future PPV-positive blocks that would be removed as eradication zones increased, the number of removed blocks increased exponentially $\left(R^{2}=99.9 \%\right)$ (Fig. 12).

\section{Discussion}

An epidemiological evaluation of the impacts of plant disease eradication programs on the temporal and spatial dynamics of an introduced plant pathogen may help to improve future plant pathogen eradication programs. Whereas many epidemiological studies utilize incidence data to evaluate disease management tactics and programs $(3,9,19,36)$, the analysis of frequency data, in special cases (such as pathogen eradication programs), may be more intuitive. For example, expressed as frequency data (actual PPV-infected trees or blocks), the PPV epidemic in Ontario had its highest peak in $2001(1,474$ PPV-positive trees), whereas the peak frequency for the number of PPV-infected trees in Pennsylvania was 399 (Fig. 1). Thus, in terms of frequency, Ontario was faced with more than three times the frequency of infected trees than Pennsylvania was challenged with. Yet, in terms of PPV incidence, PPV incidence values at the early onset were quite similar (0.8\% in Pennsylvania and $1.1 \%$ in Ontario) (Fig. 2). One disadvantage in using PPV frequency data, however, was that different temporal models best fit the frequency data (the exponential model for Pennsylvania and the linear model for Ontario). When different population growth models best fit two temporal data sets, a direct comparison of parameter estimates (i.e., slopes and $y$-intercepts) cannot be made due to the use of different dimensions (units of measure). Conversely, the advantage of using PPV incidence
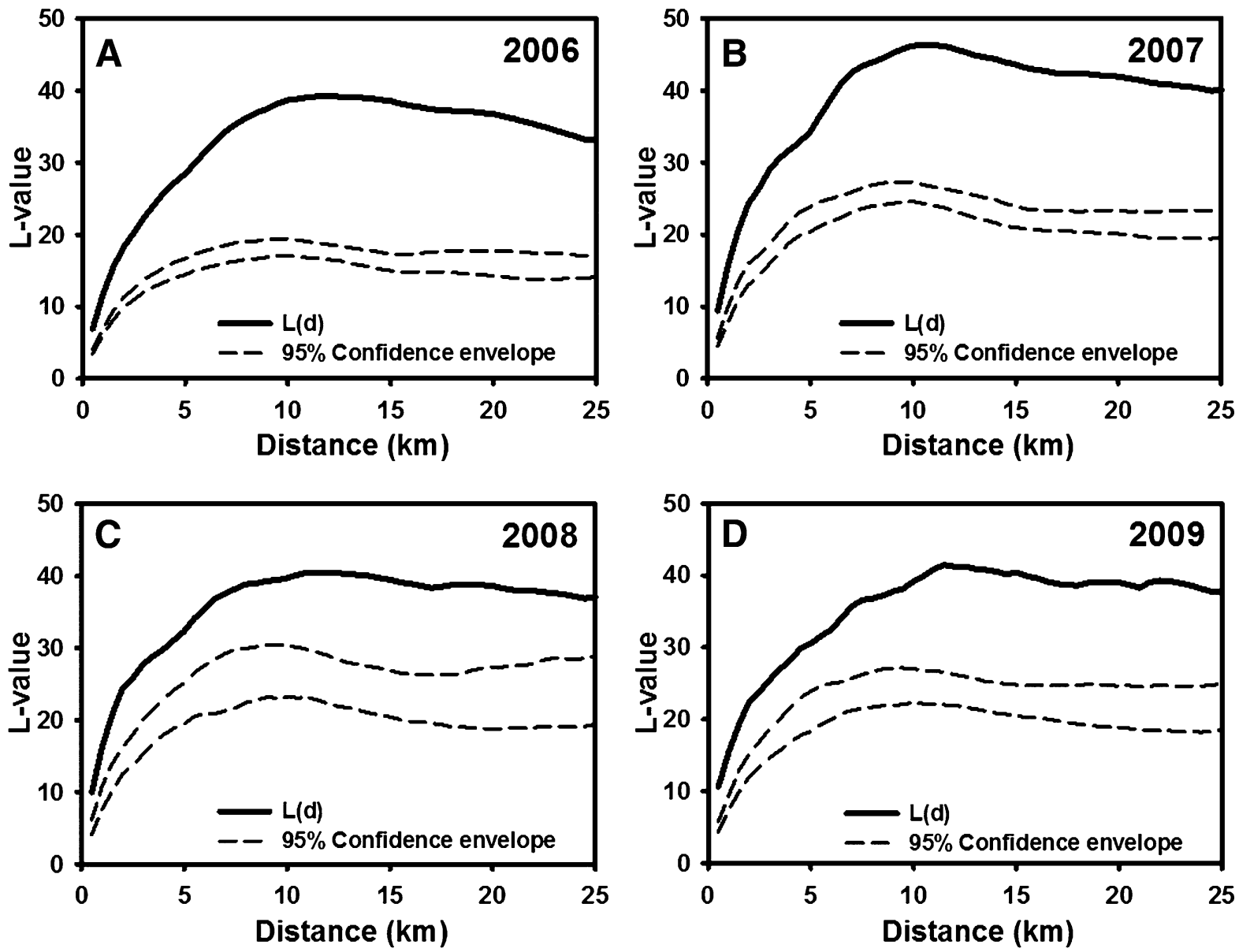

Fig. 6. Ripley's L function (solid line) using a random labeling null hypothesis to analyze the spatial dependence of PPV-positive Prunus blocks detected in Ontario in A, 2006; B, 2007; C, 2008; and D, 2009. Dashed lines are a 95\% confidence envelope based on a simulated randomized labeling of all Prunus blocks. The observed L function (solid line) within the confidence envelope (dashed lines) indicates a random pattern, above the confidence envelope a clustered pattern, and below the confidence envelope a dispersed pattern. 
data for temporal analyses was that a single model (the exponential model) best fit both incidence datasets. Therefore, a single model could be used to calculate and compare the impact that PPV eradication policies and programs had on the rate that PPV incidence decreased over time. The PPV pathogen strains that challenged both Pennsylvania and Ontario were virtually the same (the D strain), with just single, isolated occurrences of the $\mathrm{W}$ and Rec strains in Ontario (41). Thus, differences in the rates of reduction in PPV incidence over time were most likely due to differences in postdetection eradication (tree and block removal) policies or environmental factors, including block and tree density, Prunus spp. planted, or production practices $(8,11)$.

One possible explanation as to why decline in PPV incidence in Ontario was only $60 \%$ of that in Pennsylvania is that the Pennsylvania PPV sampling and testing program had a higher PPV detection
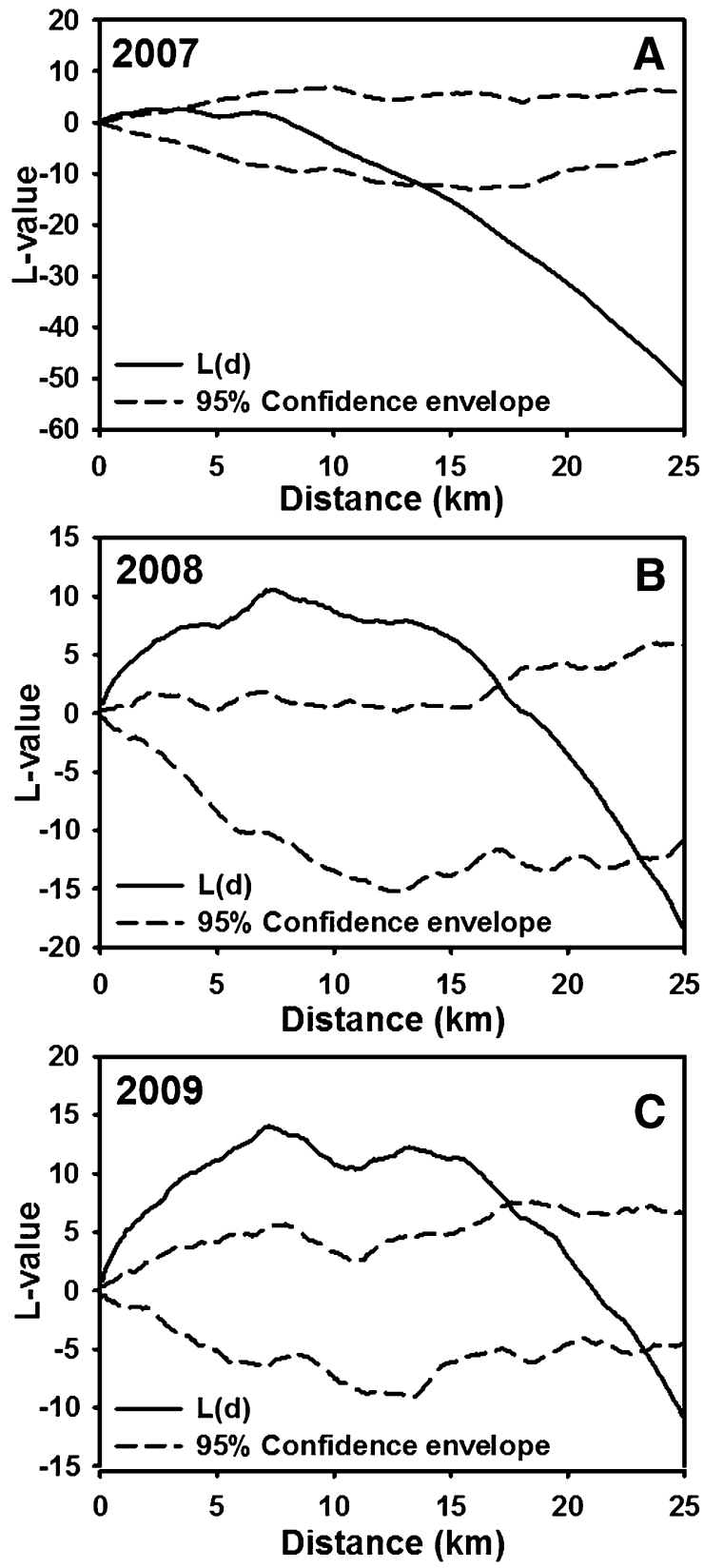

Fig. 7. Bivariate Ripley's $L$ function (solid line), with a random labeling null hypothesis, performed on consecutive years of PPV-positive Prunus blocks in Ontario in A, 2007; B, 2008; and C, 2009. Dashed lines are a 95\% confidence envelope based on a simulated randomized labeling of all Prunus blocks. The observed $L$ function (solid line) within the confidence envelope (dashed lines) indicates a random pattern, above the confidence envelope a clustered pattern, and below the confidence envelope a dispersed pattern. efficiency at the tree and block scales compared with the Ontario program (17). Gougherty et al. (17) recently conducted a simulation study that found that the Pennsylvania PPV sampling and testing program had a detection efficiency of $71.8 \%$ at the tree scale compared with $41.5 \%$ for the Ontario PPV sampling and testing program. A report by Vrient (54) provides further evidence that the ELISA kit employed in Ontario had a lower detection efficiency than the kit used in Pennsylvania since 2006. Thus, after 2006, the Ontario program would have detected just $57.7 \%$ of the PPV-positive trees that the Pennsylvania program would have detected, when the same PPVpositive trees were intensively resampled and retested using each PPV program's protocol $(16,17)$. The higher detection efficiency in Pennsylvania compared with Ontario likely resulted in a higher percentage of PPV-infected trees being detected and removed, thereby facilitating a more rapid decline in PPV incidence over time.

Spatial pattern of PPV-positive blocks. Marked point pattern spatial analysis at the block scale revealed that the spatial dynamics of PPV epidemics in Pennsylvania and Ontario were quite different. The $\mathrm{L}$ function calculated for individual years of data revealed that

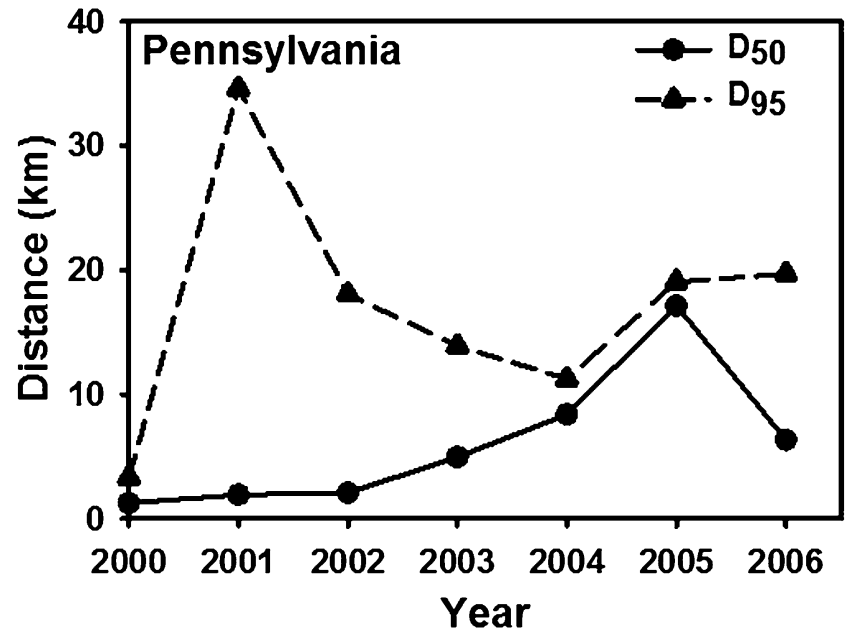

Fig. 8. Distance to $50 \%\left(D_{50}\right)$ and $95 \%\left(D_{95}\right)$ of new PPV-positive Prunus blocks in Pennsylvania plotted over time. Values represent the 50 and $95 \%$ quantiles for the minimum distances between PPV-positive Prunus blocks and the nearest PPVpositive Prunus block from the previous year.

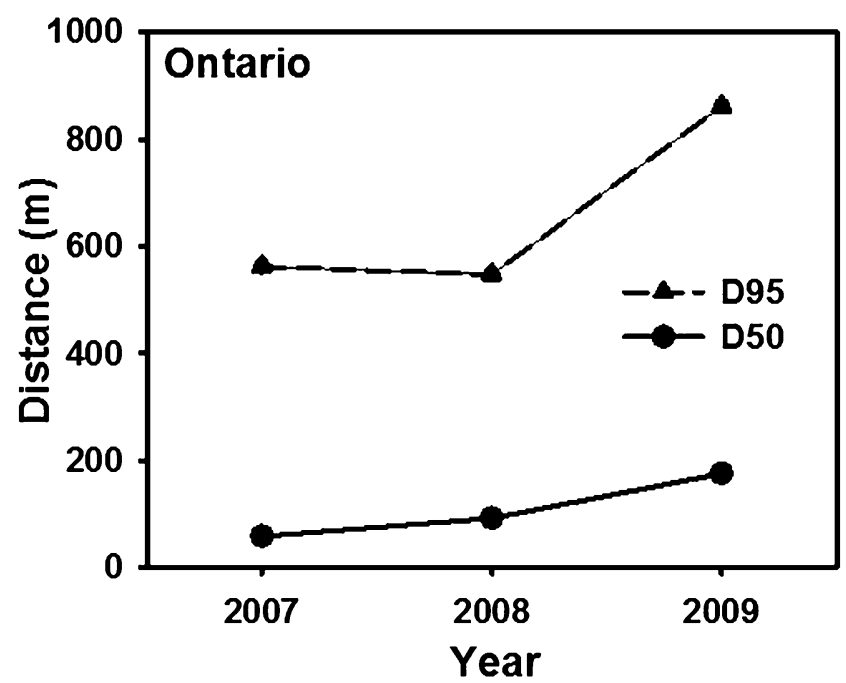

Fig. 9. Distance to $50 \%\left(D_{50}\right)$ and $95 \%\left(D_{95}\right)$ of new PPV-positive Prunus blocks in Ontario plotted over time. Values represent the $50 \%$ and $95 \%$ quantiles for the minimum distances between PPV-positive Prunus blocks and the nearest PPVpositive Prunus block from the previous year. 
PPV-positive blocks were clustered over relatively short distances in Pennsylvania (0.7 to $4.3 \mathrm{~km}$ in 2000), whereas significant clustering was observed over much longer distances in Ontario (1 to $25 \mathrm{~km}$ in 2006 to 2009), even though initial PPV incidence levels in Pennsylvania in 2000 were similar to PPV incidence levels in Ontario from 2005 through 2009 (i.e., less than 5\% PPV incidence at the tree scale). One of the factors that may have influenced spatial dynamics at the block scale is block incidence (the number of PPV-positive Prunus blocks/total number of Prunus blocks surveyed $\times 100$ ). Block incidence in Pennsylvania and Ontario was initially similar; however, frequency of PPV-positive blocks in Ontario was 256 compared with 41 in Pennsylvania. The much larger number of PPV-positive blocks in Ontario, as well a higher density of Prunus blocks per unit area, may have contributed to the clustering of PPV-positive blocks at a larger spatial scale in Ontario than in Pennsylvania.

The extent of spatial dependence found in our analysis was consistent with previous studies of PPV-positive Prunus blocks in Pennsylvania and Ontario. Gottwald (14) earlier reported that spatial dependence for PPV was present at the orchard scale for distances up to $4.3 \mathrm{~km}$ in Ontario (after accounting for the underlying patterns of all Prunus orchards). This distance is very similar to what was found when an L function analysis was applied to PPV positives at the block scale in 2000 in Pennsylvania. These findings suggest that the distribution of PPV-positive blocks in Pennsylvania and Ontario was very similar during the early stages of both epidemics; however, as the epidemic progressed in Ontario, the spatial extent and distribution of PPV-positive blocks continued to increase. In 2006, PPVpositive blocks were clustered for distances of up to $25.0 \mathrm{~km}$ in Ontario. This analysis suggests that, in 2006 to 2009, PPV-positive blocks in which individual PPV-positive trees had been removed (but not the blocks) were having an impact on the PPV health status of other Prunus blocks for distances of up to $25.0 \mathrm{~km}$ via long-distance dispersal by aphids. This interpretation was supported by applying the L function to consecutive years of Ontario's eradication survey data, which revealed that the location of future PPV-positive blocks was spatially dependent upon the location of PPV-positive blocks detected the previous year. Thus, even when PPV-positive trees were removed from PPV-positive blocks detected the previous year, PPV-positive trees and blocks that escaped detection (and therefore were not removed) may have continued to have an impact on the health status of other Prunus blocks in subsequent years.

Our finding that newly detected PPV-positive blocks in Ontario were spatially dependent upon PPV-positive blocks detected the previous year provides valuable information for policy makers to consider when establishing threshold-based (Ontario) or distancebased eradication policies. Quantification of distances to 50 and 95\% of PPV-positive values that integrated distance and time to

Table 1. Spatial pattern analysis of PPV-positive Prunus trees within 12 PPVpositive Prunus blocks in Ontario, Canada

\begin{tabular}{|c|c|c|c|c|c|}
\hline \multirow[b]{2}{*}{ Block } & \multirow[b]{2}{*}{ Incidence $(\%)$} & \multicolumn{2}{|c|}{ Within row } & \multicolumn{2}{|c|}{ Across row } \\
\hline & & $z$-score ${ }^{\mathrm{a}}$ & $\begin{array}{l}\text { Spatial } \\
\text { pattern }\end{array}$ & $z$-score ${ }^{\mathrm{a}}$ & $\begin{array}{l}\text { Spatial } \\
\text { pattern }\end{array}$ \\
\hline 1 & 0.55 & 0.15 & Random & 0.15 & Random \\
\hline 2 & 1.28 & 0.20 & Random & 0.20 & Random \\
\hline 3 & 1.50 & 0.27 & Random & 0.27 & Random \\
\hline 4 & 0.90 & 0.15 & Random & 0.15 & Random \\
\hline 5 & 1.19 & -6.72 & Clustered & 0.16 & Random \\
\hline 6 & 0.66 & $\mathrm{v} 2.82$ & Clustered & -2.82 & Clustered \\
\hline 7 & 0.41 & 0.13 & Random & 0.13 & Random \\
\hline 8 & 0.61 & 0.26 & Random & 0.26 & Random \\
\hline 9 & 0.24 & 0.13 & Random & 0.13 & Random \\
\hline 10 & 1.80 & 0.26 & Random & 1.78 & Random \\
\hline 11 & 1.00 & -7.78 & Clustered & -7.78 & Clustered \\
\hline 12 & 1.45 & 0.07 & Random & 0.07 & Random \\
\hline
\end{tabular}

a Spatial pattern of PPV trees was considered clustered within a Prunus block if the $z$-score was $<-1.64(16,25)$. quantify the spatial dynamics of PPV-positive blocks from year-toyear provided new indexes to gauge the spatial dynamics of PPV. Because $D_{50}$ and $D_{95}$ values are based on the nearest neighbor, these values are a conservative measure of pathogen spread because the nearest neighbor from the previous year is not necessarily the source of inoculum. Still, these indices provide valuable new information concerning the impacts of eradication policies on the spatial expansion and contraction of plant disease epidemics. For example, as PPV-infected blocks were removed from the epicenter, $\mathrm{D}_{95}$ values indicated that the PPV epidemic in Pennsylvania expanded between 2000 and 2001 and then contracted to a steady state between 10 and $20 \mathrm{~km}$ from 2002 to 2006; whereas, in Ontario, PPV epidemics continued to expand spatially from 2007 to 2009 . Calculating $D_{50}$ and $\mathrm{D}_{95}$ values over time may be useful in determining what future sampling and eradication distances are most appropriate to successfully achieve pathogen eradication. We propose that $D_{95}$ values may serve as a guide to establish quarantine areas that should be more intensively surveyed for new positives. For example, in Pennsylvania, 95\% of new PPV-positive blocks were detected between 10 and $20 \mathrm{~km}$ from PPV-positive blocks that were detected the previous year. This suggests that intensive surveying efforts up to distances of $20 \mathrm{~km}$ from each PPV-positive block detected the previous year may be more likely to detect a new PPV-positive block. This approach may become especially important as fewer and fewer new PPVpositive trees and blocks are detected each year, as was the case in both Pennsylvania and Ontario.

One challenge with the $\mathrm{D}_{95}$ approach, however, is that it is sometimes difficult to distinguish between biological spread of PPV and human dispersal via the movement of infected propagative material. The $\mathrm{D}_{95}$ peak in Pennsylvania in 2001, for instance, was partially the result of an outlying PPV-positive tree, far removed from other PPVpositive trees, and it is unknown whether or not this specific infection was the result of long-distance aphid dispersal or the result of grafting infected budwood. Therefore, the calculation of $\mathrm{D}_{95}$ accounts for the distances for $95 \%$ of new positives, but this statistic can be sensitive to spatial outliers. $\mathrm{D}_{50}$ values are significantly less sensitive to spatial outliers, because only $50 \%$ of new positives are included in this calculation.

Determining the distance from a previous year's pathogen-positive trees to newly detected positive trees has been used in other perennial-crop pathosystems to provide a science-based protocol for tree and block removal. Gottwald et al. (15) determined that the previous policy of removing all citrus trees within $38.1 \mathrm{~m}$ of each canker-infected citrus tree was insufficient to reduce canker spread; instead, the eradication zone around each newly detected citrus

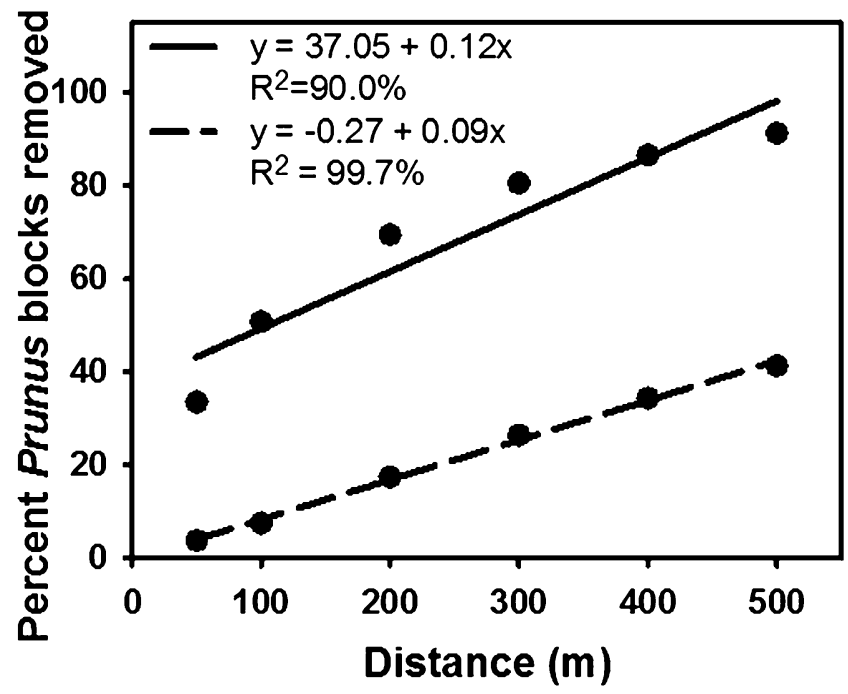

Fig. 10. Percent healthy (dashed line) and future PPV-positive blocks (solid line) that would have been removed had Ontario implemented a distance-based Prunus block removal policy (2006 to 2009). 
canker tree should be much larger $(>579 \mathrm{~m})$. Although it has been suggested that a similar distance-based removal policy could be deployed to eradicate PPV in Ontario (29), due to the tremendous challenges concerning the successful eradication of PPV in Ontario, as of 2011, the CFIA has shifted from an eradication-based PPV strategy in Ontario to a PPV management strategy (7). Even when switching to a management-based containment strategy, these distance-based analyses could still be used to establish the size and geographic boundaries of quarantine zones that may be required for regulatory purposes. For example, distance-based analyses might be used to geospatially define regulated areas where it would be forbidden to move potentially infected planting material (such as infected budwood or nursery stock) out of quarantined (regulated) areas. Science-based geospatial information might also be used to define quarantined areas that require more intensive (targeted) sampling (37).

Spatial distribution of PPV-positive trees within Prunus blocks. The random spatial patterns of PPV-positive trees observed in 9 of the 12 Prunus blocks in Ontario is consistent with other within-block spatial analyses of PPV-positive trees conducted in Pennsylvania and elsewhere $(10,14)$. The reason why PPV-positive trees in 3 of the 12 blocks displayed a clustered pattern may be due to the eradication policy used in Ontario. All of the blocks analyzed had relatively low levels of PPV incidence and all but one block (block 6) had PPV-positive trees detected in at least two previous survey years. Because PPV-positive trees in Ontario are typically removed the year they are the detected, PPV incidence in any recurring positive blocks would likely remain low, which may explain why 9 of the 12 blocks analyzed had primarily random spatial patterns. In a separate study that measured spatial dependence over time in the Soybean mosaic virus-aphid vector pathosystem, Steinlage et al. (46) noted that within-field random spatial patterns tended to occur at the early stages of an epidemic (i.e., when virus incidence was low). The mostly random withinblock spatial pattern observed in our study may have been the result of Prunus blocks in Ontario having been kept in the perpetual early stages of a PPV epidemic (due to the annual removal of PPVpositive trees), resulting in a low block PPV incidence with random spatial patterns.

These findings have a direct impact on the sampling design that should be employed when scouting for new PPV-positive trees and blocks. Random sampling designs should not be used when the spatial pattern of diseased plants may be clustered (35). Because the distribution of PPV-infected trees was clustered in 25\% of the Prunus blocks that we analyzed, a systematic sampling design should continue to be employed in PPV surveys, because this sampling design accommodates both clustered and random spatial patterns of diseased plants $(3,19,26,27,46)$.

Another important component to consider when developing sampling protocol is to determine when is the best time to sample during the year. PPV-positive trees in Pennsylvania tended to be detected earlier in the year compared with Ontario, with $90 \%$ of detections occurring by week 27 . Furthermore, the time interval between the first PPV detection in Pennsylvania (week 19) and when $90 \%$ of the detections had occurred was just 8 weeks. In Ontario (2006 to 2009), however, the first PPV detection occurred in week 21 and did not reach $90 \%$ of the total number of PPV detections until week 34 (13 weeks later). This difference is likely due, in part, to the higher latitude and later growing season in Ontario. Other researchers have reported that virus titers in PPV-positive trees can drop below PPV detection levels using ELISA during warm weather $(47,48,51)$. The higher seasonal temperatures in Pennsylvania compared with Ontario (due to differences in latitude), likely contributed to the difference in the seasonal patterns of PPV detection (Fig. 4).

The results generated in our study show that different approaches to eradication can have vastly different effects on the spatial and temporal dynamics of PPV epidemics. Quantifying the spatial and temporal dynamics of an epidemic can provide critical new information that can have important implications when developing and optimizing disease eradication and management programs. Moreover,

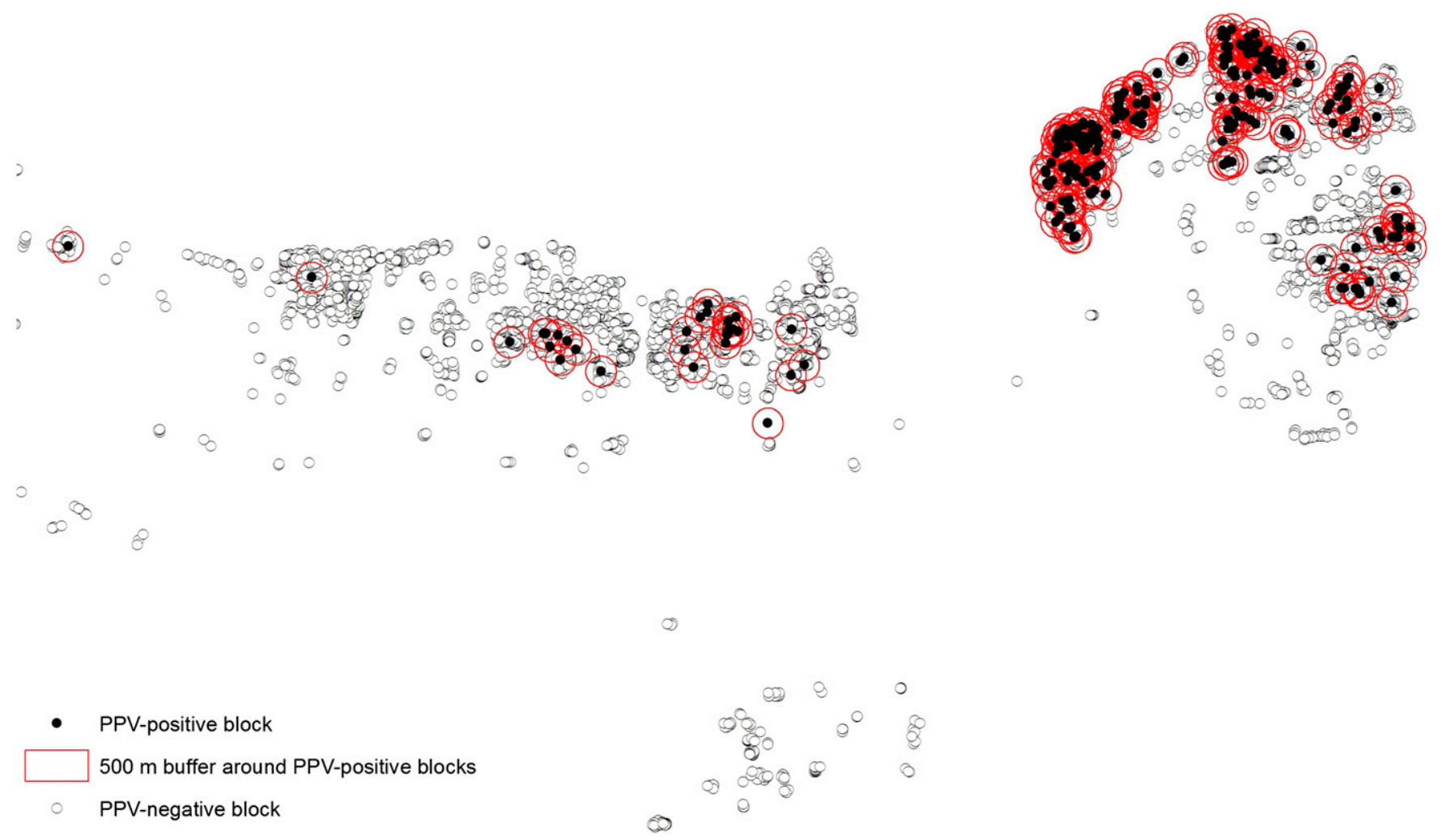

Fig. 11. PPV-positive blocks and PPV-negative blocks in Ontario in 2006 that would be required to be removed if Ontario implemented a 500-m removal distance, as was used in Pennsylvania. Approximately $50 \%$ of the healthy blocks in Ontario would have been required to be removed in 2006 . Geographic boundaries were removed from the map to preserve the anonymity of the growers. 

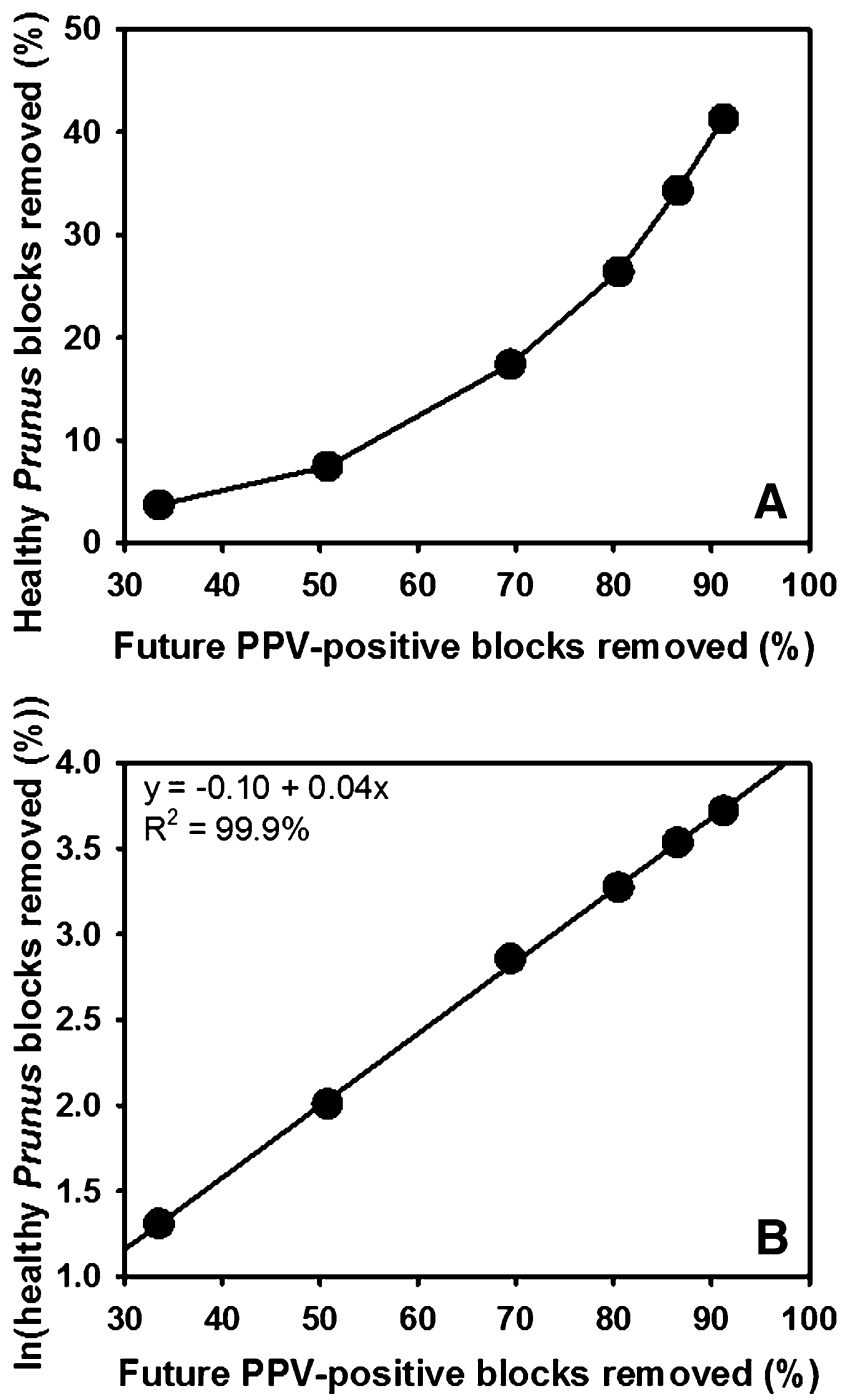

Fig. 12. A, Percentage of Prunus blocks removal in Ontario, Canada (y-axis) with respect to the percentage of future PPV-positive blocks removed (x-axis) as eradication block removal distance increases from 100 - to $500-\mathrm{m}$ diameter circles and $\mathbf{B}$, least squares regression of the percentage of healthy Prunus blocks removal with respect to the percentage of future PPV-positive blocks removal if a 100- to 500-m eradication diameter had been employed in Ontario, Canada.

determining where and when new positives are likely to occur, at multiple spatial scales, can provide valuable information for policy makers and regulatory personnel. Results generated in our study, for instance, suggest that the more stringent eradication measures in Pennsylvania resulted in the successful eradication of PPV in Pennsylvania, whereas Ontario abandoned its less stringent eradication policy and has now adopted a PPV management strategy that utilizes surveillance and monitoring activities to prevent the spread of PPV.

\section{Acknowledgments}

Funding for this research was provided by the United States Department of Agriculture Economic Research Service. We thank N. Richwine and R. Welliver of the PDA and V. Galvin, E. Wierenga, L. Maurice, and C. Green at the CFIA for providing us with access to the PDA and CFIA plum pox eradication program spatial data.

\section{Literature Cited}

1. Atanassov, D. 1932. Plum Pox: A new virus disease. Ann. Univ. Sofia Fac. Agric. Silvic. 11:49-69.

2. Boulila, M., and Ravelonandro, M. 2006. Plum pox virus (PPV) in Tunisia. EPPO Bull. 36:216.

3. Byamukama, E., Robertson, A. E., and Nutter, F. W., Jr. 2010. Quantification of temporal and spatial dynamics of Bean pod mottle virus at different spatial scales. Online publication. Plant Health Prog. 10.109.1094/PHP-2010-05XX01-SY.

4. Caglayan, K. 2006. Plum pox virus (PPV) in Turkey. EPPO Bull. 36:216-217.

5. Cambra, M., Capote, N., Myrta, A., and Llacer, G. 2006. Plum pox virus and the estimated costs associated with sharka disease. EPPO Bull. 36:202-204.

6. Cambra, M. A., Serra, J., Cano, A., and Cambra, M. 2006. Plum pox virus (PPV) in Spain. EPPO Bull. 36:215.

7. Canadian Food Inspection Agency.2011. Online publication. http://www inspection.gc.ca/plants/plant-protection/diseases/plum-pox-virus/monitoringand management-program/eng/1323887724804/1323889930176.

8. Candresse, T., and Cambra, M. 2006. Causal agent of sharka disease: Historical perspective and current status of Plum pox virus strains. EPPO Bull. 36:239-246.

9. Coelho-Netto, R. A., and Nutter, F. W., Jr. 2005. Use of GPS and GIS technologies to map the prevalence of Moko disease of banana in the Amazonas region of Brazil. Pages 431-436 in: 3rd Int. Bacterial Wilt Symp. White River, South Africa. American Phytopathological Society, St. Paul, MN.

10. Dallot, S., Gottwald, T., Labonne, G., and Quiot, J. B. 2003. Spatial pattern analysis of sharka disease (Plum pox virus strain $\mathrm{M}$ ) in peach orchards of southern France. Phytopathology 93:1543-1552.

11. Damsteegt, V. D., Scorza, R., Stone, A. L., Schneider, W. L., Webb, K., Demuth, M., and Gildow, F. E. 2007. Prunus host range of Plum pox virus (PPV) in the United States by aphid and graft inoculation. Plant Dis. 91:18-23.

12. Di Terlizzi, B., and Boscia, D. 2006. Plum pox virus (PPV) in Italy. EPPO Bull. 36:210.

13. Dixon, P. M. 2002. Ripley's K function. Pages 1796-1803 in: Encyclopedia of Environmetrics. A. H. El-Shaarawi and W. W. Piegorsch, eds. Wiley \& Sons, Chichester, UK.

14. Gottwald, T. R. 2006. Epidemiology of sharka disease in North America. EPPO Bull. 36:279-286.

15. Gottwald, T. R., Sun, X., Riley, T., Graham, J. H., Ferrandino, F., and Taylor, E. L. 2002. Geo-referenced spatiotemporal analysis of the urban citrus canker epidemic in Florida. Phytopathology 92:361-377.

16. Gougherty, A. V., and Nutter, F. W., Jr. 2012. An epidemiological comparison of the US and Canadian Plum pox virus eradication programs. Online publication. Plant Health Prog. 10.1094/PHP-2012-0723-03-RS.

17. Gougherty, A. V., Pazdernik, K. T., Kaiser, M. S., and Nutter, F. W., Jr. Evaluation of sampling and testing efficiencies of Plum pox virus eradication programs in Pennsylvania and Ontario. Plant Dis. (In press.)

18. Gougherty, A., Welliver, R., Richwine, N., and Nutter, F. W., Jr. 2010. Spatial and temporal analyses of Plum pox virus survey data. (Abstr.) Phytopathology 100:S42.

19. Habili, N., and Nutter, F. W., Jr. 1997. Temporal and spatial analysis of grapevine leafroll-associated virus 3 in Pinot Noir grapevines in Australia. Plant Dis. 81:625-628.

20. Ismaeil, F. 2006. Plum pox virus (PPV) in Syria. EPPO Bull. 36:216.

21. Jarausch, W. 2006. Plum pox virus (PPV) in Germany. EPPO Bull. 36:209.

22. Kaiser, M. S., and Caragea, P. 2009. Exploring dependence with data on spatial lattices. Biometrics 65:857-865.

23. Labonne, G., and Dallot, S. 2006. Epidemiology of sharka disease in France. EPPO Bull. 36:267-270.

24. Levy, L., Damsteegt, V., Scorza, R., and Kolber, M. 2000. Plum pox potyvirus disease of stone fruits. Online publication. http://www.apsnet.org/ publications/apsnetfeatures/pages/plumpoxpotyvirus.aspx.

25. Levy, L., Damsteegt, V., and Welliver, R. 2000. First report of Plum pox virus (Sharka disease) in Prunus persica in the United States. Plant Dis. 84:202.

26. Lu, X., Robertson, A., Byamukama, E., and Nutter, F., Jr. 2010. Prevalence, incidence, and spatial dependence of Soybean mosaic virus in Iowa. Phytopathology 100:931-940.

27. Madden, L., Louie, R., Abt, J., and Knoke, J. 1982. Evaluation of tests for randomness of infected plants. Phytopathology 72:195-198.

28. Matić, S., Durić, G., and Myrta, A. 2006. Plum pox virus (PPV) in Bosnia and Herzegovina. EPPO Bull. 36:205-206.

29. Mitham, P.2010. Ontario faces challenges to Plum pox virus eradication. Good Fruit Grower. April 2010. Online publication. http://www.goodfruit.com/ ontario-faces-challenges-to-plum-pox-virus-eradication/

30. Mumford, R. A. 2006. Plum pox virus (PPV) in the United Kingdom. EPPO Bull. 36:217.

31. Muñoz, M., and Collao, M. 2006. Plum pox virus (PPV) in Chile. EPPO Bull. $36: 207$.

32. NAPPO.2004. Guidelines for phytosanitary action following detection of Plum pox virus. NAPPO Regional Standards for Phytosanitary Measures http://www.nappo.org/en/data/files/download/PDF/RSPM18-18-10-04-e.pdf.

33. NAPPO.2013. Plum pox virus regulated areas removed in Orleans and Wayne Counties, New York. Online publication. http://www.pestalert.org/oprDetail. cfm?oprID $=557$

34. Navratil, M., Safarova, D., Karesova, R., and Petrzik, K. 2006. Plum pox virus (PPV) in China. EPPO Bull. 36:207.

35. Nutter, F. W., Jr. 1997. Quantifying the temporal dynamics of plant virus epidemics: A review. Crop Prot. 16:603-618

36. Nutter, F. W., Jr. 2007. The role of plant disease epidemiology in developing successful integrated disease management programs. Pages 43-77. in: Genera 
Concepts in Integrated Pest and Disease Management. A. Ciancio and K. G. Mukerji, eds. Springer-Verlag, Dordrecht, The Netherlands.

37. Nutter, F. W., Jr., Byamukama, E., Coelho-Netto, R. A., Eggenberger, S. K., Gleason, M. L., Gougherty, A., Robertson, A. E., and Van Rij, N. 2011. Integrating GPS, GIS, and remote sensing technologies with disease management principles to improve plant health. Pages 59-90 in: GIS Applications in Agriculture-Invasive Species. S. Clay, ed. Taylor \& Francis Group LLC, Boca Raton, FL.

38. Nutter, F. W., Jr., Rubsam, R. R., Taylor, S. E., Harri, J. A., and Esker, P. D. 2002. Use of geospatially-referenced disease and weather data to improve sitespecific forecasts for Stewart's disease of corn in the US corn belt. Comput. Electron. Agric. 37:7-14.

39. Nutter, F. W., Jr., Van Rij, N., Eggenberger, S. K., and Holah, N. 2010. Spatial and temporal dynamics of plant pathogens. Pages 27-50 in: Precision Crop Protection-the Challenge and Use of Heterogeneity. E.-C. Oerke, R. Gerhards, G. Menz, and R. A. Sikora, eds. Springer, New York.

40. Ortego, J., Zotto, A. D., Caloggero, S., Raigón, J. M., Gasparini, M. L., Ojeda, M. E., and Ducasse, D. A. 2006. Plum pox virus (PPV) in Argentina. EPPO Bull. 36:205.

41. Ravelonandro, M., Vrient, A., Briard, P., and Mason, M. 2008. Controversial considerations between nucleotide diversity of the $3^{\prime}$ terminal region of Plum pox virus and differences in viral serotypes. J. Plant Pathol. 90: S1.47-S1.56.

42. Ripley, B. D. 1981. Spatial Statistics. Wiley, New York.

43. Snover-Clift, K. L., Clement, P. A., Jablonski, R., Mungari, R. J., Mavrodieva, V. A., Negi, S., and Levy, L. 2007. First report of Plum pox virus on plum in New York State. Plant Dis. 91:1512.

44. Speich, P. 2006. Plum pox virus (PPV) in France. EPPO Bull. 36:208-209.

45. Stamo, B., and Myrta, A. 2006. Plum pox virus (PPV) in Albania. EPPO Bull. $36: 205$
46. Steinlage, T. A., Hill, J., and Nutter, F., Jr. 2002. Temporal and spatial spread of Soybean mosaic virus (SMV) in soybeans transformed with the coat protein gene of SMV. Phytopathology 92:478-486.

47. Stobbs, L. 2009. Plum pox virus: Studies on virus distribution and sampling methods. United States-Canada Plum pox virus Update Conference. Niagara Falls, Ontario, Canada.

48. Thompson, D. 2003. Woody host range of Canadian PPV-D. Annual meeting of NE1006: Eradication, Containment, and/or Management of Plum Pox Disease (Sharka). November 17-18, 2003, Shepherdstown, WV

49. Thompson, D. 2006. Control and monitoring: Control strategies for Plum pox virus in Canada. EPPO Bull. 36:302-304.

50. Thompson, D., McCann, M., MacLeod, M., Lye, D., Green, M., and James, D. 2001. First report of Plum pox potyvirus in Ontario, Canada. Plant Dis. 85:97.

51. United States Department of Agriculture. 2007. Recovery plan for Plum pox virus (Sharka) of stone fruit. National Plant Disease Recovery System. Online publication. http://www.ars.usda.gov/SP2UserFiles/Place/00000000/ opmp/Plum\%20Pox\%20PPV\%2070222.pdf.

52. van Maanen, A., and Xu, X.-M. 2003. Modeling plant disease epidemics. Eur. J. Plant Pathol. 109:669-682.

53. Varveri, C. 2006. Plum pox virus (PPV) in Greece. EPPO Bull. 36:209-210.

54. Vrient, A. 2006. External validation of Agdia's Plum pox virus (PPV) reagen set, catalog number SRA 31505. Agdia, Inc. Elkhart, IN

55. Wiegand, T., and Moloney, K. A. 2004. Rings, circles, and null-models for point pattern analysis in ecology. Oikos 104:209-229.

56. Youssef, S. A., and Shalaby, A. 2006. Plum pox virus (PPV) in Egypt. EPPO Bull. 36:208.

57. Zadoks, J. C., and Schein, R. D. 1979. Epidemiology and Plant Disease Management. Oxford University Press, New York.

58. Zamharir, M. G., Bashir, N. S., and Khakvar, R. 2006. Plum pox virus (PPV) in Iran. EPPO Bull. 36:210. 